Prepared for the U.S. Department of Energy under Contract DE-AC05-76RL01830

\title{
PNNL Technical Support to the Implementation of EMTA and EMTA-NLA Models in Autodesk ${ }^{\circledR}$ Moldflow $^{\circledR}$ Packages
}

\author{
Ba Nghiep Nguyen ${ }^{(a)}$ and Jin Wang ${ }^{(b)}$
}

(a) Pacific Northwest National Laboratory, P.O. Box 999, Richland, WA 99352

(b) Autodesk, Inc. at Ithaca, NY 14850

December 2012

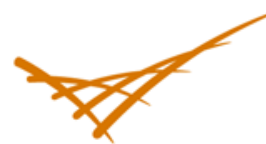

Pacific Northwest

NATIONAL LABORATORY

Proudly Operated by Battelle Since 1965 


\title{
DISCIAAIMER
}

This report was prepared as an account of work sponsored by an agency of the United States Government. Neither the United States Government nor any agency thereof, nor Battelle Memorial Institute, nor any of their employees, makes any warranty, express or implicd, or assumes any legal liability or responsibility for the accuracy, completeness, or usefulness of any information, apparatus, product, or process disclosed, or represents that its use would not infringe privately owned rights. Reference herein to any specific commercial product, process, or service by trade namc, trademark, manufacturer, or otherwise does not necessarily constitute or imply its endorsement, recommendation, or favoring by the United States Government or any agency thereof, or Battelle Memorial Institute. The views and opinions of authors expressed herein do not necessarily state or reflect those of the United States Government or any agency thereof

\author{
PACIFIC NORTHWEST NATIONAI, I.ABORATORY \\ operated by \\ BAI'I'ELLE \\ for the \\ UNITED STATES DFPARTMENT OF FNERGY \\ under Contract DE-ACO5-76RL01830 \\ Printed in the United States of America \\ Available to DOE and DOE contractors from the \\ Office of Scientific and Technical Information, \\ P.O. Box 62, Oak Ridge, TN 37831-0062; \\ ph: (865) 576-8401 \\ fax: $(865) 576-5728$ \\ email: reports@adonis.osti.gov \\ Available to the public from the National Technical Information Service, \\ U.S. Department of Commerce, 5285 Port Royal Rd., Springfield, VA 22161 \\ ph: (800) 553-6847 \\ fax: $(703) 605-6900$ \\ email: orders@ntis.fedworld.gov \\ online ordering: http://www.ntis.gov/ordering.htm
}

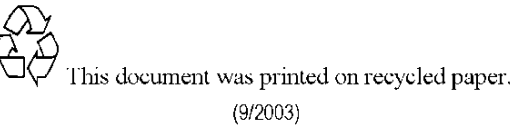

(9/2003) 


\title{
PNNL Technical Support to the Implementation of EMTA and EMTA-NLA Models in Autodesk ${ }^{\circledR}$ Moldflow ${ }^{\circledR}$ Packages
}

\author{
Ba Nghiep Nguyen ${ }^{(a)}$ and Jin Wang ${ }^{(b)}$,
}

\footnotetext{
(a) Pacific Northwest National Laboratory, P.O. Box 999, Richland, WA 99352

(b) Autodesk, Inc. at Ithaca, NY 14850
}

December 2012

Prepared for

the U.S. Department of Energy

under Contract DE-AC05-76RL01830 



\section{Executive Summary}

Recently, long-fiber thermoplastic (LFT) composites have attracted great interest within the automotive industry since these materials offer much better structural performance (e.g. higher elastic moduli, strength, and durability) than their short-fiber analogues, and they can be processed through injection molding with some specific tool design. However, to be able to compute the properties of injection molded LFTs, there is an important need to develop process and property prediction models as well as computational tools to predict the microstructure and resulting mechanical properties of these composites. Under Phase II of the Predictive Engineering project funded by the Lightweight Materials program in the DOE Office of Vehicle Technologies, Pacific Northwest National Laboratory (PNNL) developed the property prediction (constitutive) models for injection-molded LFTs that describe the linear and nonlinear behaviors of these materials ([1-5]). In the meantime, PNNL built the computational capabilities named EMTA (Eshelby-Mori-Tanaka Approach) [6] and EMTA-NLA [7] (Eshelby-Mori-Tanaka Approach to Non-Linear Analysis) that have implemented the developed constitutive models for LFTs. The models explore the standard and improved Eshelby-Mori-Tanaka approaches that consider elastic fibers distributed in a thermoplastic matrix whose behavior can be linear or nonlinear depending on the loading prescribed to the composite.

In an effort to transfer the technologies developed under the Predictive Engineering project to the American automotive and plastics industries, PNNL has obtained the approval of the DOE Office of Vehicle Technologies to provide Autodesk, Inc. with the technical support for the implementation of the basic property prediction models of EMTA and EMTA-NLA in the Autodesk ${ }^{\circledR}$ Moldflow ${ }^{\circledR}$ packages. The present report describes this effort. 


\section{Contents}

PNNL Technical Support to the Implementation of EMTA and EMTA NLA Models in Autodesk ${ }^{\circledR}$ Moldflow $^{\circledR}$ Packages .................................. iii Executive Summary ...................................................................................................... 1

1.0 Introduction ............................................................................................................... 3

2.0 Basic Property Prediction Models Developed for LFTs......................... 3

2.1 The EMTA/EMTA-NLA Model for Elastic Properties Accounting for Fiber Length

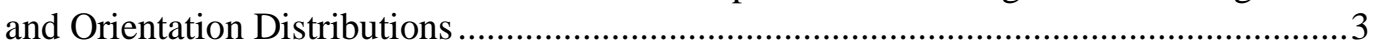

2.2 The EMTA/EMTA-NLA Fiber/Matrix Debonding Model ..............................................

3.0 Property Prediction Using ASMI and EMTA Models ............................ 8

3.1 Prediction of Elastic Properties Distributions in Molded parts .........................................8

3.2 Effect of Fiber/Matrix Debonding on Elastic Properties................................................12

4.0 Stress-Strain Responses and Damage Analysis .................................. 15

4.1 Analyses of Specimens Cut from the Long-glass-fiber/PA6,6 Plaque.............................15

4.2 Analyses of Specimens Cut from the Long-glass-fiber/PP Plaque .................................18

5.0 Conclusions ........................................................................................................... 21

6.0 Acknowledgements .............................................................................. 21

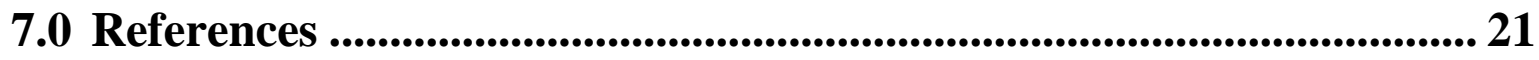




\subsection{Introduction}

Under the Predictive Engineering effort, PNNL developed linear and nonlinear property prediction models for LFTs. These models were implemented in PNNL's EMTA and EMTANLA codes. While EMTA is a standalone software for the computation of the composites thermoelastic properties, EMTA-NLA presents a series of nonlinear models implemented in ABAQUS $^{\circledR}$ via user subroutines for structural analyses. In all these models, it is assumed that the fibers are linear elastic while the matrix material can exhibit a linear or typical nonlinear behavior depending on the loading prescribed to the composite. The key idea is to model the constitutive behavior of the matrix material and then to use an Eshelby-Mori-Tanaka approach (EMTA) combined with numerical techniques for fiber length and orientation distributions to determine the behavior of the as-formed composite.

The basic property prediction models of EMTA and EMTA-NLA have been subject for implementation in the Autodesk ${ }^{\circledR}$ Moldflow $^{\circledR}$ software packages. These models are the elastic stiffness model accounting for fiber length and orientation distributions, the fiber/matrix interface debonding model, and the elastic-plastic models. The PNNL elastic-plastic models for LFTs describes the composite nonlinear stress-strain response up to failure by an elastic-plastic formulation associated with either a micromechanical criterion to predict failure or a continuum damage mechanics formulation coupling damage to plasticity. All the models account for fiber length and orientation distributions as well as fiber/matrix debonding that can occur at any stage of loading. This report summarizes the recent results from Autodesk Simulation Moldlow Insight (ASMI) analyses using the EMTA models and EMTA-NLA/ABAQUS ${ }^{\circledR}$ analyses for further assessment of the EMTA-NLA models to support their implementation in Autodesk Moldflow Structural Alliance (AMSA).

PNNL's technical support to Autodesk, Inc. included (i) providing the theoretical property prediction models as described in published journal articles and reports, (ii) providing explanations of these models and computational procedure, (iii) providing the necessary LFT data for process simulations and property predictions, and (iv) performing ABAQUS/EMTANLA analyses to further assess and illustrate the models for selected LFT materials.

\subsection{Basic Property Prediction Models Developed for LFTs}

\subsection{The EMTA/EMTA-NLA Model for Elastic Properties Accounting for Fiber Length and} Orientation Distributions

The stiffness matrix of a unidirectional (UD) fiber composite containing a fiber length distribution developed in EMTA and EMTA-NLA is given by:

$$
\mathbf{H}=\frac{\int_{0}^{\infty} \mathbf{H}^{*}(l / d) p(l) d l}{\int_{0}^{\infty} p(l) d l}
$$


where $\mathbf{H}^{*}(l / d)$ is the stiffness matrix of the UD fiber composite having the aspect ratio $l / d$. The expression of $\mathbf{H}^{*}(l / d)$ is based on the Eshelby-Mori-Tanaka approach developed in References [8-11]. $p(l)$ is the probability density function that can be expressed for number or weight of fibers. From a theoretical viewpoint one can argue for using the weight distribution of length $p(l)=w(l)$ rather than the number distribution $f(l)$ since the process of averaging over the length distribution is essentially a volume average, and $w(l)$ is proportional to the volume of fibers of length $l$. The elastic stiffness of the actual composite having an as-formed fiber orientation state is computed using the orientation averaging method [12]:

$$
\begin{aligned}
\bar{H}_{i j k l}= & B_{1} \tilde{A}_{i j k l}+B_{2}\left(A_{i j} \delta_{k l}+A_{k l} \delta_{i j}\right)+B_{3}\left(A_{i k} \delta_{j l}+A_{i l} \delta_{j k}+A_{j l} \delta_{i k}+A_{j k} \delta_{i l}\right) \\
& +B_{4} \delta_{i j} \delta_{k l}+B_{5}\left(\delta_{i k} \delta_{j l}+\delta_{i l} \delta_{j k}\right)
\end{aligned}
$$

where the coefficients $B_{i}(i=1,5)$ are the invariants of the stiffness tensor of the UD transversely isotropic composite (Equation (1)). These coefficients are given in [12]. $A_{i j}$ and $\tilde{A}_{i j k l}$ are the second and fourth-order orientation tensors, respectively, and $\delta_{i j}$ is the identity tensor. $A_{i j}$ is either predicted by a process model or measured, and then the ORE orthotropic closure approximation [13] is used to estimate the fourth-order tensor $\tilde{A}_{i j k l}$ from $A_{i j}$.

\subsection{The EMTA/EMTA-NLA Fiber/Matrix Debonding Model}

In EMTA [6] and EMTA-NLA [7], partial fiber/matrix debonding is modeled by a modified Eshelby-Mori-Tanaka (EMT) formulation by Qu [14] that accounts for imperfect fiber/matrix interfaces. It is assumed that partial debonding manifests as fiber/matrix sliding without separation. This assumption leads to the following expression for the fiber/matrix interface compliance tensor, $\eta_{i j}$

$$
\eta_{i j}=\beta\left(\delta_{i j}-n_{i} n_{j}\right)
$$

where $\beta$ is a parameter that expresses the debonding intensity, and $\delta_{i j}$ is the identity tensor. $n_{i}$ and $n_{j}$ are the components of the unit normal vector at the fiber/matrix interface. $\beta=0$ represents the perfect fiber/matrix interface while $\beta \rightarrow \infty$ corresponds to free fiber/matrix sliding. Equation (3) is used in the modified EMT formulation to compute the stiffness matrix of the reference UD composite [6-7].

In the presence of partially debonded fiber/matrix interfaces, the following expression for the modified Eshelby tensor is used:

$$
\mathbf{S}^{*}=\mathbf{S}+(\mathbf{I}-\mathbf{S}): \mathbf{L}: \mathbf{H}_{\mathrm{m}}:(\mathbf{I}-\mathbf{S})
$$

where S, I and $\mathbf{H}_{\mathrm{m}}$ are the Eshelby tensor, identity tensor, and stiffness tensor of the matrix material, respectively. The fourth-order tensor $\mathbf{L}$ has the dimension of a compliance tensor. For cylindrical long fibers whose length are much greater than their average radius $(l / r \rightarrow \infty)$, $\mathbf{L}$ is given by: 


$$
\mathbf{L}=\beta r(\mathbf{P}-\mathbf{Q})
$$

where $r$ is the fiber radius, and the components of the fourth-order tensors $\mathbf{P}$ and $\mathbf{Q}$ for cylindrical and ellipsoidal inclusions are provided in [14]. Introducing Equation (4) into the modified EMT formulation, the following expression is obtained for the stiffness tensor of a twophase composite:

$$
\mathbf{H}^{*}=\left[\left(1-\mu_{\mathrm{f}}\right) \mathbf{H}_{\mathrm{m}}+\mu_{\mathrm{f}} \mathbf{H}_{\mathrm{f}}: \mathbf{A}_{\mathrm{f}}\right]:\left[\left(1-\mu_{\mathrm{f}}\right) \mathbf{I}+\mu_{\mathrm{f}} \mathbf{A}_{\mathrm{f}}+\mu_{\mathrm{f}} \mathbf{L}: \mathbf{H}_{\mathrm{f}}: \mathbf{T}\right]^{-1}
$$

where $\mu_{\mathrm{f}}$ and $\mathbf{H}_{\mathrm{f}}$ are the volume fraction and stiffness tensor of the fiber phase, respectively. $\mathbf{A}_{\mathrm{f}}$ is the fiber-strain concentration tensor given by:

$$
\mathbf{A}_{\mathrm{f}}=\mathbf{T}:\left[\left(1-\mu_{\mathrm{f}}\right) \mathbf{I}+\mu_{\mathrm{f}} \mathbf{T}\right]^{-1}
$$

with $\mathbf{T}$ being defined in terms of the modified Eshelby tensor, $\mathbf{S}^{*}$ given by Equation (4) as $\mathbf{T}=\left[\mathbf{I}+\mathbf{S}^{*}: \mathbf{H}_{\mathrm{m}}^{-1}:\left(\mathbf{H}_{\mathrm{f}}-\mathbf{H}_{\mathrm{m}}\right)\right]^{-1}$. Finally, the application of the orientation averaging technique to Equation (2) allows the computation of the stiffness tensor of the partially debonded composite containing a fiber orientation distribution.

\subsection{The EMTA-NLA elastic-plastic models}

The details of the model formulation are reported in [2-3, 7]. The first EMTA-NLA elasticplastic model applies an incremental EMTA procedure to compute the elastic-plastic stress-strain response of an aligned fiber composite defined as the reference composite that contains the same fiber length distribution as the actual composite. The fibers are assumed to be elastic while the matrix is elastic-plastic and obeys the Ramberg-Osgood relation:

$$
\bar{\varepsilon}_{\mathrm{m}}=\bar{\varepsilon}_{\mathrm{m}}^{\mathrm{e}}+\bar{\varepsilon}_{\mathrm{m}}^{\mathrm{p}}=\frac{\bar{\sigma}_{\mathrm{m}}}{E_{\mathrm{m}}}+\left(\frac{\sigma_{0}}{E_{\mathrm{m}}}\right)\left(\frac{\bar{\sigma}_{\mathrm{m}}}{\sigma_{0}}\right)^{n}
$$

where $\bar{\varepsilon}_{\mathrm{m}}$ and $\bar{\sigma}_{\mathrm{m}}$ are the total matrix equivalent strain and stress, respectively. $\sigma_{0}$ and $n$ are the material coefficients and are defined as the reference stress and power-law exponent. $E_{\mathrm{m}}, \bar{\varepsilon}_{\mathrm{m}}^{\mathrm{e}}$, and $\bar{\varepsilon}_{\mathrm{m}}^{\mathrm{p}}$ are the matrix elastic modulus, equivalent elastic and plastic strains, respectively.

The computation of the elastic-plastic response for a discontinuous fiber composite starts from the elastic solution by the Eshelby-Mori-Tanaka approach (Equations (1) to (6)). The key idea is to replace the elastic stiffness tensor of the matrix material in these equations by its instantaneous tangent stiffness tensor that can be obtained from the matrix uniaxial stress-strain response. In EMTA-NLA, the Ramberg-Osgood relation (8) is used to represent the elasticplastic behavior of the matrix material. Accordingly, the instantaneous tangent modulus of the matrix material is given by: 


$$
E_{\mathrm{m}}^{\mathrm{t}}=\frac{E_{\mathrm{m}}}{1+n \sigma_{0}^{1-n} \bar{\sigma}_{\mathrm{m}}^{n-1}}
$$

The computation of the current matrix tangent modulus allows calculation of the current matrix tangent stiffness tensor, and therefore, the current tangent stiffness tensor of the composite ( $\overline{\mathbf{H}}^{\mathrm{t}}$ ) can be determined using Equations (1) and (2), or Equations (6) and (2). Next, the matrix stress increment is calculated to update the matrix stress. The matrix equivalent stress is obtained using the $J_{2}$ deformation theory of plasticity:

$$
\bar{\sigma}_{\mathrm{m}}=\sqrt{\frac{3}{2} \sigma_{i j}^{\prime \mathrm{m}} \sigma_{i j}^{\prime \mathrm{m}}}
$$

where $\sigma_{i j}^{\prime m}$ is the matrix deviatoric stress tensor. The computation of $\bar{\sigma}_{\mathrm{m}}$ allows the calculation of the matrix tangent modulus at the end of the current increment by Equation (9). This quantity is saved to start the next increment of the loading process. Finally, the overall stress increment of the composite is computed to update the overall stress at the end of the current increment:

$$
\Delta \boldsymbol{\sigma}=\overline{\mathbf{H}}^{\mathrm{t}} \Delta \boldsymbol{\varepsilon}
$$

At each load increment, failure is predicted using the Van Hattum-Bernado model [15] that was modified by Nguyen et al. [2] for an elastic-plastic composite by considering at each load increment an "equivalent elastic composite" which contains the same fiber length and orientation distributions as the actual composite but a matrix whose elastic modulus is given by the current secant modulus of the actual matrix material. The failure criterion reads:

$$
f=\boldsymbol{\sigma}: \overline{\widetilde{\mathbf{F}}}: \boldsymbol{\sigma}=1
$$

where $\widetilde{\widetilde{\mathbf{F}}}$ is the fourth-order strength tensor that is obtained by applying the fiber orientation averaging technique to the fourth-order strength tensor, $\tilde{\mathbf{F}}$. A method to compute this tensor for an elastic-plastic composite is given in Nguyen et al. [2]. In EMTA-NLA, the overall stress at the end of each increment is used to evaluate criterion (12). If the failure criterion is verified for a given integration point of a finite element, the composite stress and stiffness at this point are reduced to zero in a small number of load steps using a vanishing element technique [2-3]:

$$
\begin{array}{ll}
n<K: & \overline{\mathbf{H}}_{\text {failure }}^{\mathrm{t}}=\overline{\mathbf{H}}^{\mathrm{t}}(f=1)-\frac{n \overline{\mathbf{H}}^{\mathrm{t}}(f=1)}{K} \\
n \geq K: & \overline{\mathbf{H}}_{\text {failure }}^{\mathrm{t}}=\boldsymbol{\alpha}
\end{array}
$$

where $\overline{\mathbf{H}}^{\mathrm{t}}(f=1)$ is the composite stiffness at the failure initiation, $n$ is the load step number starting from the step at which failure occurs, and $K$ is a prescribed value. The components of $\boldsymbol{\alpha}$ are taken to be very small $\left(\sim 10^{-8} \mathrm{MPa}\right)$ to represent a vanishing stiffness. The stress vanishes according to:

$$
\boldsymbol{\sigma}=\overline{\mathbf{H}}_{\text {failure }}^{\mathrm{t}}: \boldsymbol{\varepsilon}
$$




\section{The Elastic-Plastic Damage Model}

Nguyen and Kunc [3] extended the Nguyen et al. elastic-plastic model [2] for injectionmolded LFT composites to account for progressive damage coupled with plasticity in the matrix material. Considering isotropic damage by matrix microcracking to be phenomenologically described by the damage variable $D$ and using the principle of strain equivalence [16], the matrix equivalent strain is given by the modified Ramberg-Osgood relation as [3]:

$$
\bar{\varepsilon}_{\mathrm{m}}=\frac{\bar{\sigma}_{\mathrm{m}}}{E_{\mathrm{m}}(1-D)}+\frac{\sigma_{0}}{E_{\mathrm{m}}}\left(\frac{\bar{\sigma}_{\mathrm{m}}}{\sigma_{0}(1-D)}\right)^{n}=\frac{\overline{\widetilde{\sigma}}_{\mathrm{m}}}{E_{\mathrm{m}}}+h \overline{\widetilde{\sigma}}_{\mathrm{m}}^{n}
$$

where the "tilde" symbol denotes an effective quantity based on the principle of strain equivalence, and $h$ is given by: $h=\sigma_{0}^{1-n} / E_{\mathrm{m}}$. The matrix equivalent stress can be expressed in terms of the matrix equivalent plastic strain as:

$$
\bar{\sigma}_{\mathrm{m}}=(1-D) k\left(\bar{\varepsilon}_{\mathrm{m}}^{\mathrm{p}}\right)^{1 / n}
$$

where $k=(1 / h)^{1 / n}$ is the hardening coefficient.

Using the deformation theory of plasticity assuming proportional loading, an evolution law for $D$ is sought in terms of stress and plastic strain quantities. To this end, EMTA-NLA uses the Lemaitre-Chaboche three-dimensional damage model in deformation for isotropic hardening materials [17]:

$$
D=\frac{D_{\mathrm{c}}}{\bar{\varepsilon}_{\mathrm{m}}^{\mathrm{R}}-\bar{\varepsilon}_{\mathrm{m}}^{\mathrm{D}}}\left(\left[\frac{2}{3}\left(1+v_{\mathrm{m}}\right)+3\left(1-2 v_{\mathrm{m}}\right)\left(\frac{\sigma_{\mathrm{m}}^{\mathrm{h}}}{\bar{\sigma}_{\mathrm{m}}}\right)^{2}\right] \bar{\varepsilon}_{\mathrm{m}}^{\mathrm{p}}-\bar{\varepsilon}_{\mathrm{m}}^{\mathrm{D}}\right)
$$

where $\bar{\varepsilon}_{\mathrm{m}}^{\mathrm{D}}$ and $\bar{\varepsilon}_{\mathrm{m}}^{\mathrm{R}}$ are the equivalent plastic strains at damage initiation (damage threshold) and at rupture, respectively, and $D_{\mathrm{c}}$ is the value of $D$ at rupture. $v_{\mathrm{m}}$ is Poisson's ratio, and $\sigma_{\mathrm{m}}^{\mathrm{h}}$ the hydrostatic stress in the matrix. A rate form of $D$ reads:

$$
\dot{D}=\frac{D_{\mathrm{c}}}{\bar{\varepsilon}_{\mathrm{m}}^{\mathrm{R}}-\bar{\varepsilon}_{\mathrm{m}}^{\mathrm{D}}}\left(\left[\frac{2}{3}\left(1+v_{\mathrm{m}}\right)+3\left(1-2 v_{\mathrm{m}}\right)\left(\frac{\sigma_{\mathrm{m}}^{\mathrm{h}}}{\bar{\sigma}_{\mathrm{m}}}\right)^{2}\right] \dot{\bar{\varepsilon}}_{\mathrm{m}}^{\mathrm{p}}\right)
$$

The composite stress/strain response is obtained using an incremental EMTA method [3] that provides the relationship between the overall effective stress and strain increments:

$$
\Delta \tilde{\sigma}_{i j}=\bar{H}_{i j k l} \Delta \varepsilon_{k l}
$$

where the composite tangent stiffness tensor $\bar{H}_{i j k l}$ is affected by both plasticity and damage of the matrix material. The computation procedure uses the current tangent modulus of the matrix material given by 


$$
E_{\mathrm{m}}^{\mathrm{t}}=\frac{E_{\mathrm{m}}}{1+\frac{n E_{\mathrm{m}}}{k\left(\bar{\varepsilon}_{\mathrm{m}}^{\mathrm{p}}\right)^{1-n / n}}}(1-D)
$$

in the incremental EMTA procedure where $D$ is computed using Equation (17) or (18).

Fiber/matrix debonding is modeled by a modified Mori-Tanaka formulation summarized in Section 2.2 that uses a parameter controlling the fiber/matrix interface compliance. While EMTA [6] considers slightly weakened interfaces with constant values of the interface compliance for the calculation of the resulting composite elastic properties, EMTA-NLA [3,7] uses a progressive debonding law linearly coupled with the matrix damage variable to describe debonding from eventually a perfect interface to a complete debond where total frictional fiber/matrix sliding can occur. Damage evolves according to Equation (17) up to a critical state ( $D=D_{\text {c }}$ ) at which total failure occurs. Total failure leading to initiation and propagation of a macroscopic crack is captured using a vanishing element technique presented above (Equations (13)).

\subsection{Property Prediction Using ASMI and EMTA Models}

Autodesk, Inc. has implemented the EMTA elastic and fiber/matrix debonding models in ASMI. After mold filling simulation, fiber length and orientation predictions by ASMI for the final composite part or component, it is necessary to predict the elastic properties of the asformed LFT composite and the extent of warpage caused by thermal stresses during processing. The EMTA models and their implementation in ASMI help solve these problems. ASMI computation of elastic properties and warpage for other composite systems such as compressionmolded composite can be found in Reference [18].

\subsection{Prediction of Elastic Properties Distributions in Molded parts}

The first application illustrates the ASMI analysis of a large 50\%-weight-fraction long-glassfiber/polyamide 6,6 (PA6,6) plaque (305 mm x 305 mm x 2.8 mm”) from injection molding simulation to elastic properties prediction using the EMTA elastic model accounting for fiber length and orientation distribution [1]. Figure 1 shows the ASMI finite element mesh for the injection molding simulation of this plaque. Before any property predictions, it was necessary to check fiber orientation and length predictions as the predicted fiber orientation and length were used in subsequent property predictions. Figures 2(a) and 2(b) present the contours of fiber orientation tensor components $A_{11}$ and $A_{22}$ in a core layer of this plaque (the 1- and 2-directions are aligned with the $\mathrm{X}$ and $\mathrm{Y}$-directions, respectively). Figure 3(a) provides the predicted and experimental through-thickness distributions of the orientation tensor components $A_{11}$ and $A_{22}$ in the flow and cross-flow direction on the centerline at $132 \mathrm{~mm}$ from the gate while Figure 3(b) shows the predicted and measured fiber length distributions for the same region. The predicted weight-average length and the average values of $A_{11}$ and of $A_{22}$ agree with the experimental results within 15\%. Predicted fiber orientation and length distributions were then used to compute the elastic properties for the plaque as illustrated in Figure 4 that shows the contours of the elastic moduli expressed in the principal orientation axes. The predicted flow (18030 MPa) 
and cross-flow (13071 MPa) moduli at the center of the plaque agree with the experimental results (16100 MPa and $11400 \mathrm{MPa})$ within 15\%.

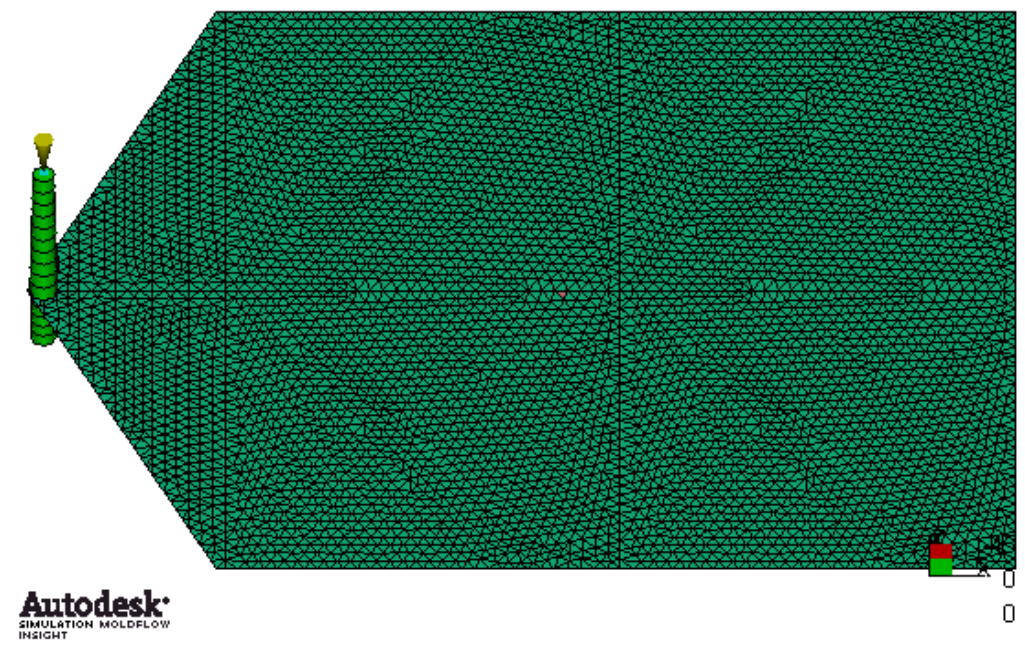

Figure 1. ASMI model for analyzing of the large long-glass-fiber/PA6,6 plaque.

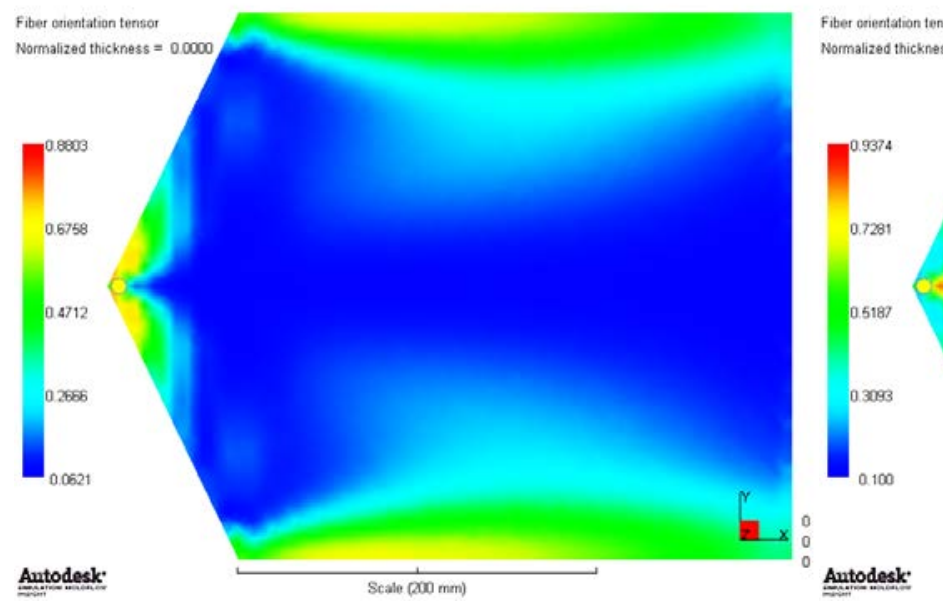

(a)

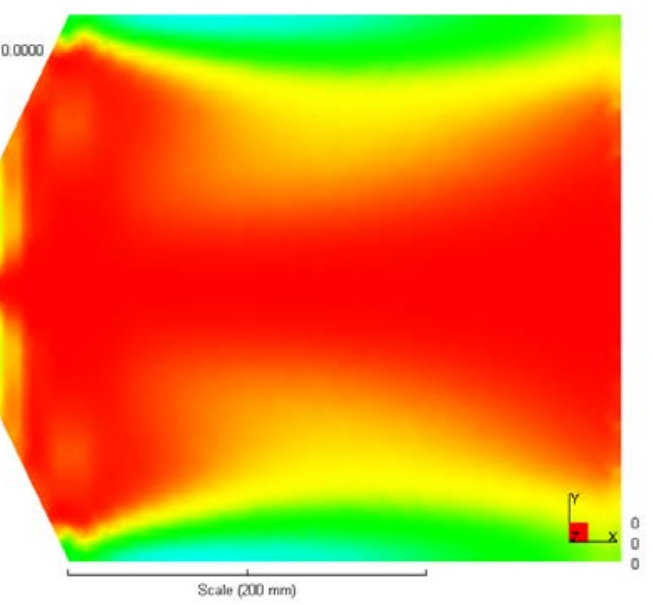

(b)

Figure 2. Predicted distributions of fiber orientation components (a) $A_{11}$ and (b) $A_{22}$ in the core of the long-glass-fiber/PA6,6 plaque. 

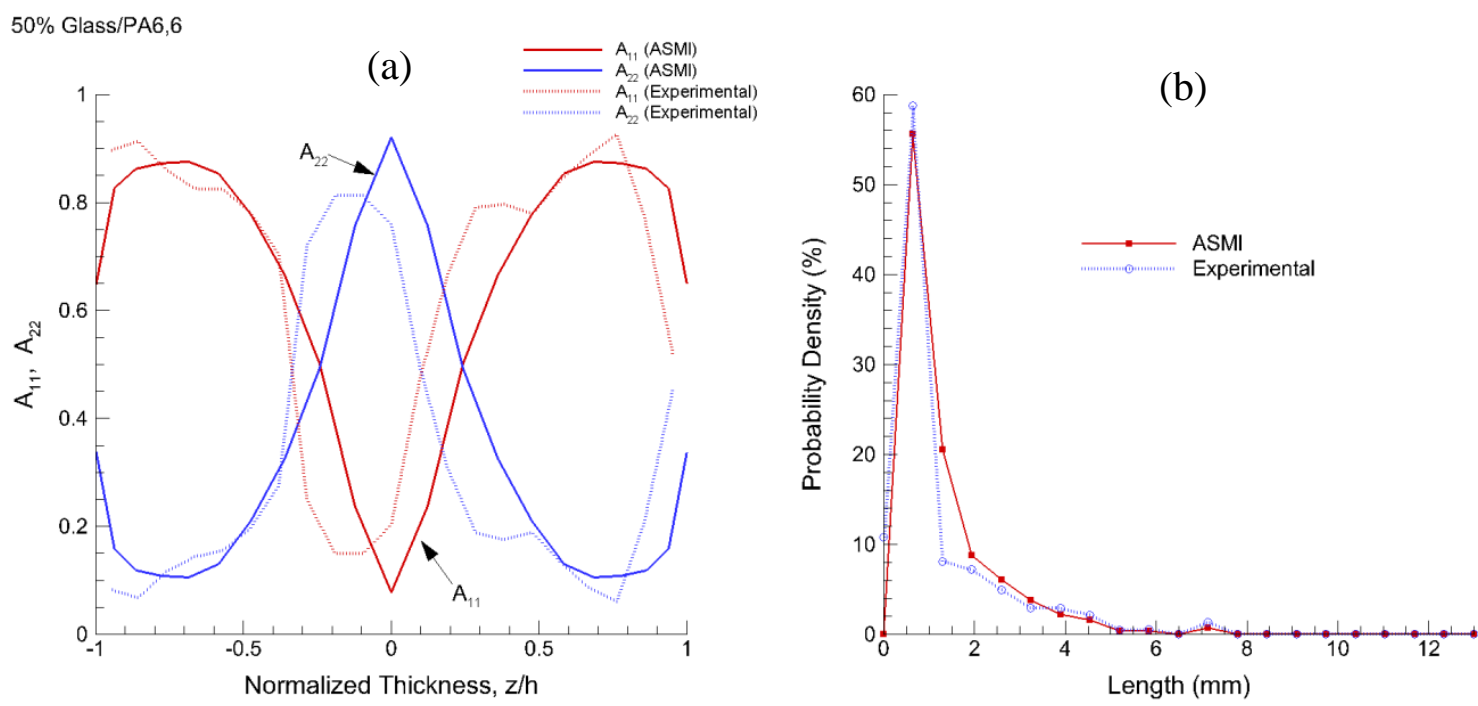

Figure 3. (a) Predicted and measured fiber orientation distribution, and - (b) Predicted and measured fiber length distribution for the center of the long-glass-fiber/PA6,6 plaque.

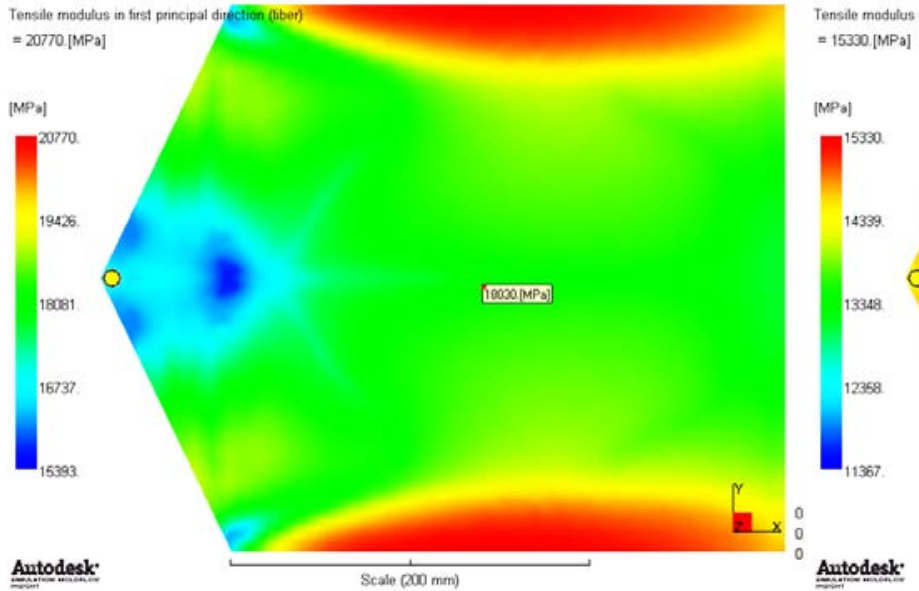

(a)

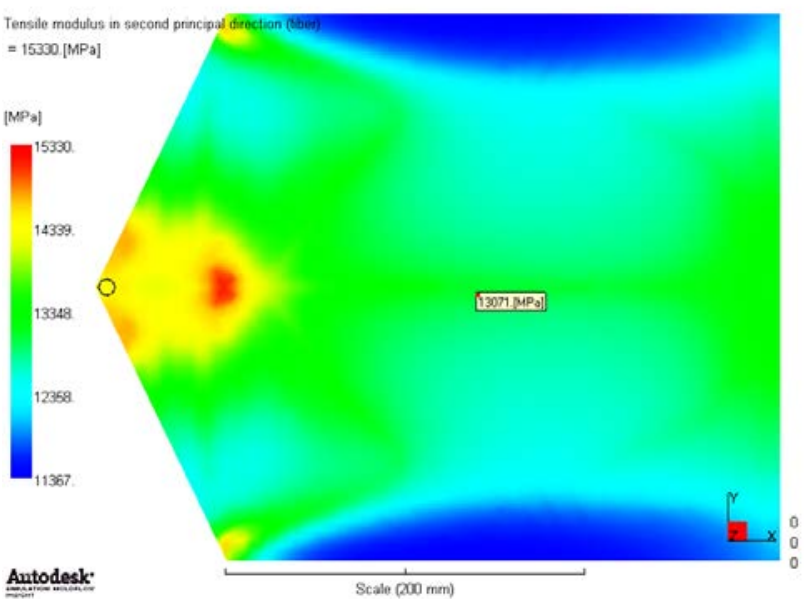

(b)

Figure 4. Predicted principal elastic moduli for the long-glass-fiber/PA6,6 plaque.

A similar analysis was conducted for an edge-gated 40\%-weight-fraction long-glassfiber/polypropylene plaque (90 mm x $80 \mathrm{~mm}$ x 3mm) studied in [1-3]. Figures 5(a) and 5(b) present the contours of fiber orientation tensor components $A_{11}$ and $A_{22}$ in a core layer of this plaque. Figure 6(a) provides the predicted and experimental through-thickness distributions of the orientation tensor components $A_{11}$ and $A_{22}$ in the flow and cross-flow directions on the centerline at $45 \mathrm{~mm}$ from the gate while Figure 6(b) shows the predicted and measured fiber length distributions for the same region. Good agreements (within 15\%) in terms of average quantities between predicted and measured values are found. Predicted fiber orientation and length distributions were then used to compute the elastic properties for the plaque as illustrated in Figure 7 that shows the contours of the elastic moduli expressed in the principal orientation 
axes. The predicted flow (6067 MPa) and cross-flow (7422 MPa) moduli at the center of the plaque are in excellent agreement with the experimental results (6063 MPa and $7211 \mathrm{MPa}$ ) within $3 \%$.

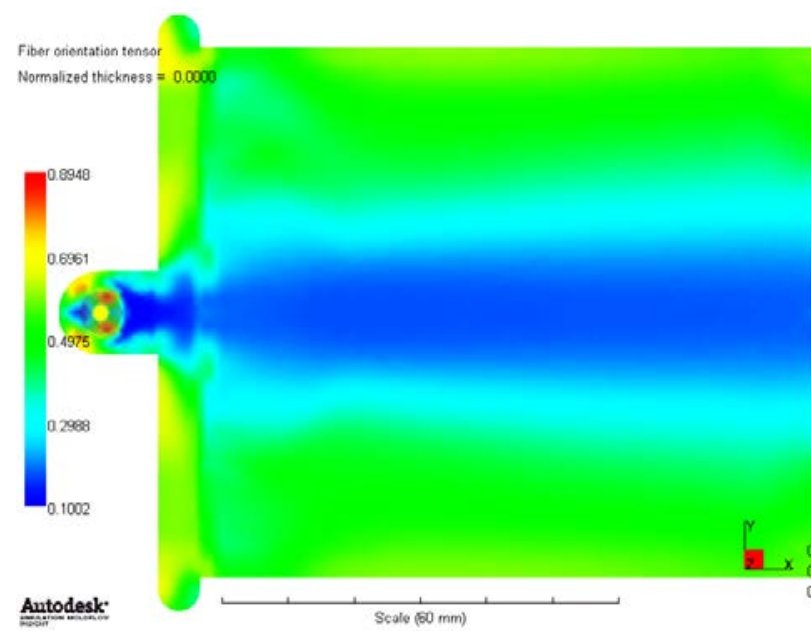

(a)

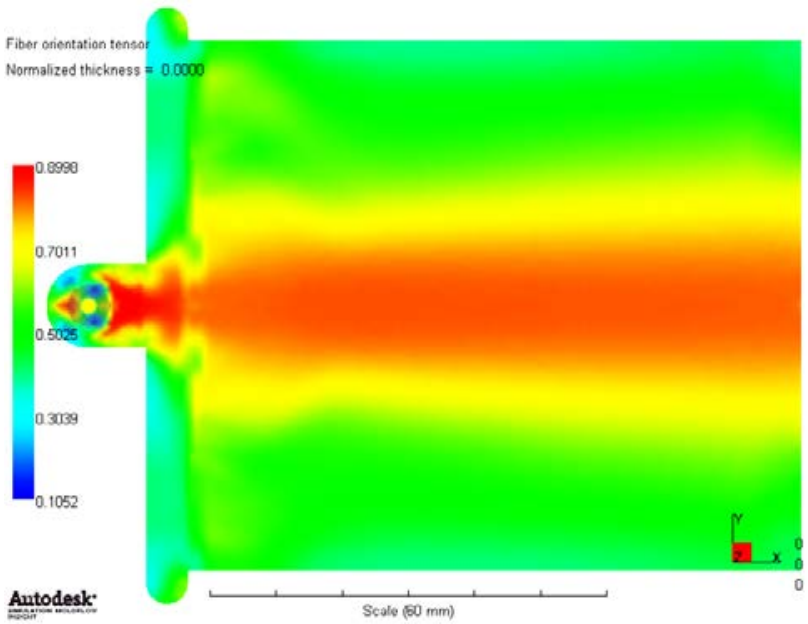

(b)

Figure 5. Predicted distributions of fiber orientation components (a) $A_{11}$ and (b) $A_{22}$ in the core of the long-glass-fiber/PP plaque.

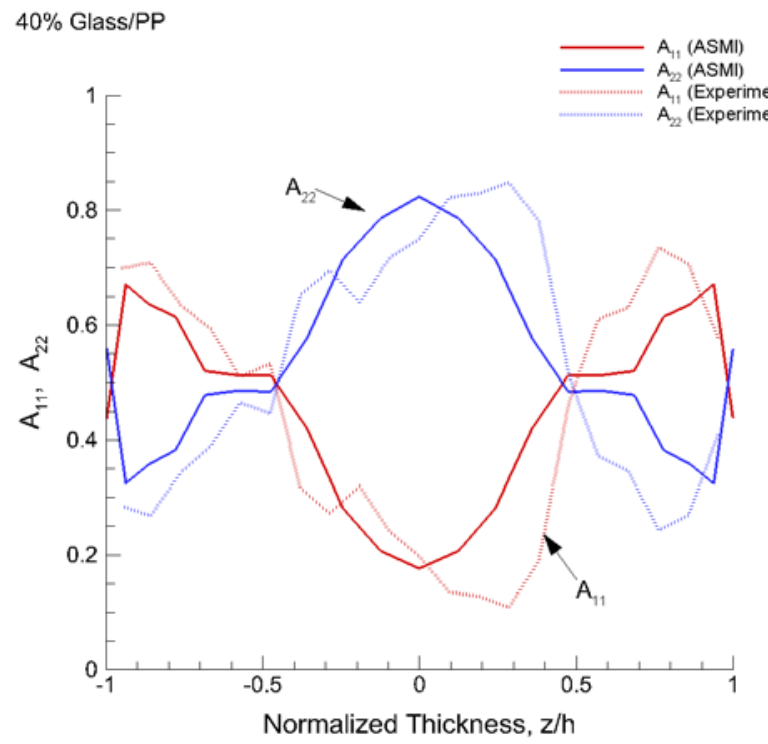

(a)

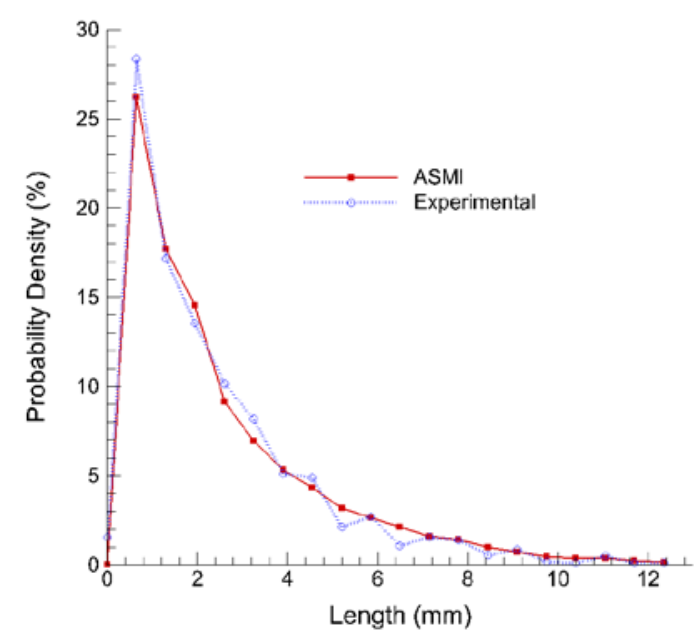

(b)

Figure 6. (a) Predicted and measured fiber orientation distribution, and - (b) Predicted and measured fiber length distribution for the center of the long-glass-fiber/PP plaque. 


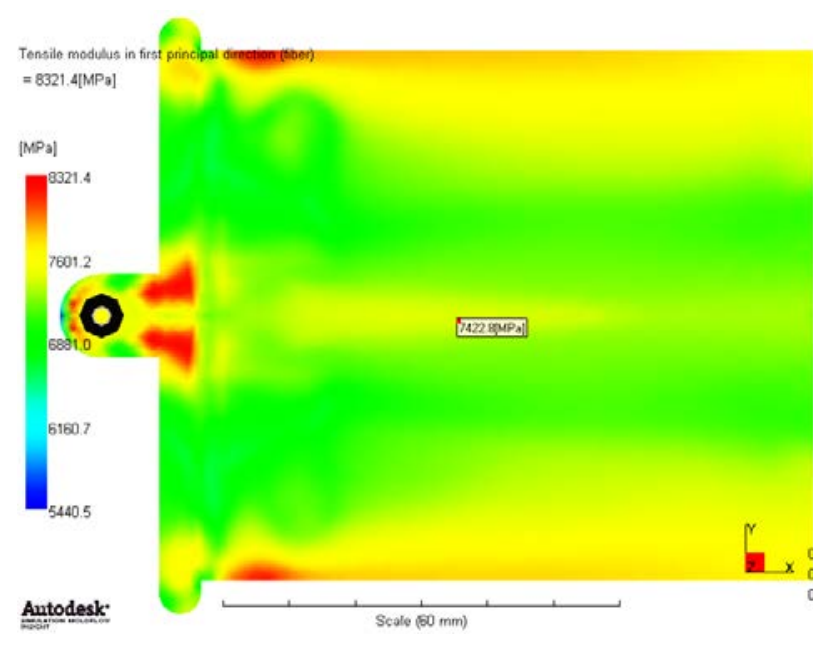

(a)

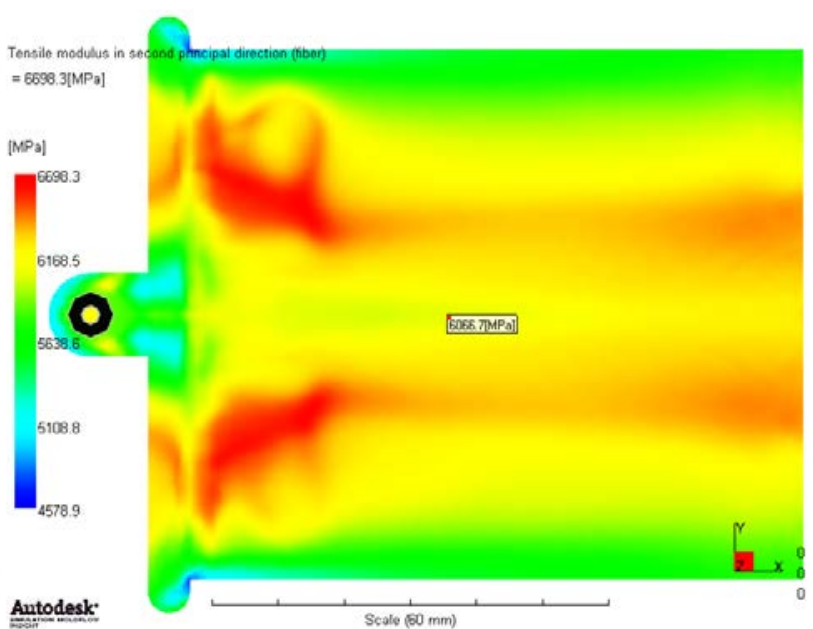

(b)

Figure 7. Predicted principal elastic moduli for the long-glass-fiber/PA6,6 plaque.

\subsection{Effect of Fiber/Matrix Debonding on Elastic Properties}

Fiber/matrix debonding can occur in the final composite after processing. The experimental observation and data for the extent of debonding are not available for the studied LFT plaques. However, it is recognized that the extent of debonding depends on processing condition and the quality of fiber/matrix adhesion. Fiber/matrix interface imperfections and partial debonding after processing reduce the mechanical properties of the as-formed composite. Fiber/matrix debonding in EMTA [4] is modeled by a modified EMT approach. The debonding model uses a damage parameter (named $\beta$ ) controlling the fiber/matrix interface compliance (Section 2.2).

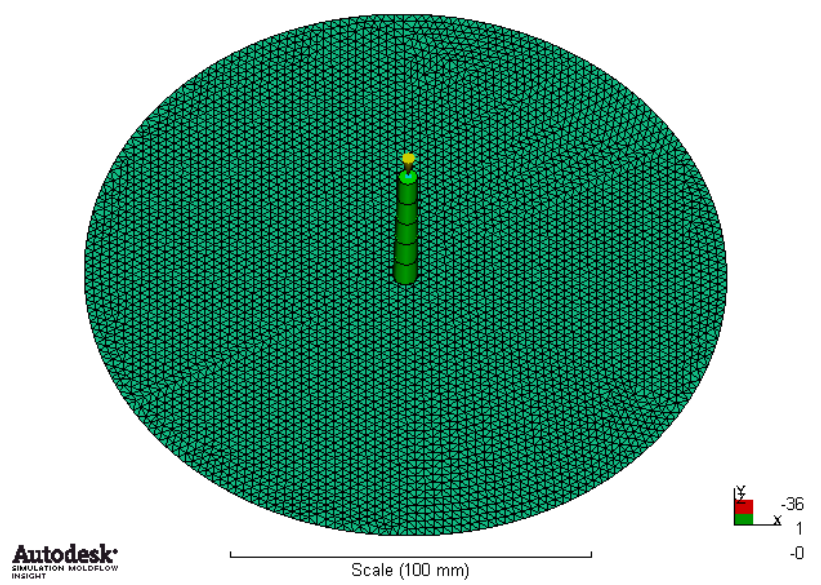

Figure 8. ASMI model for analyzing the long-glass-fiber/PP center-gated disk.

The next example illustrates the ASMI analysis for a 40\%-weight-fraction long-glass/PP center-gated disk (Figure 8) to study the effect of fiber/matrix debonding on the composite 
elastic properties. Before proceeding to property prediction, ASMI predictions of fiber orientation and length distributions for the disk were checked based on the $15 \%$ accuracy criterion. Figure 9(a) provides the predicted and experimental through-thickness distributions of the orientation tensor components $A_{11}$ and $A_{22}$ in the flow and cross-flow direction at $35 \mathrm{~mm}$ from the injection center while Figure 9(b) shows the predicted and measured fiber length distributions for the same region. The predicted weight-average length and the average values of $A_{11}$ and of $A_{22}$ agree with the experimental results within $15 \%$.
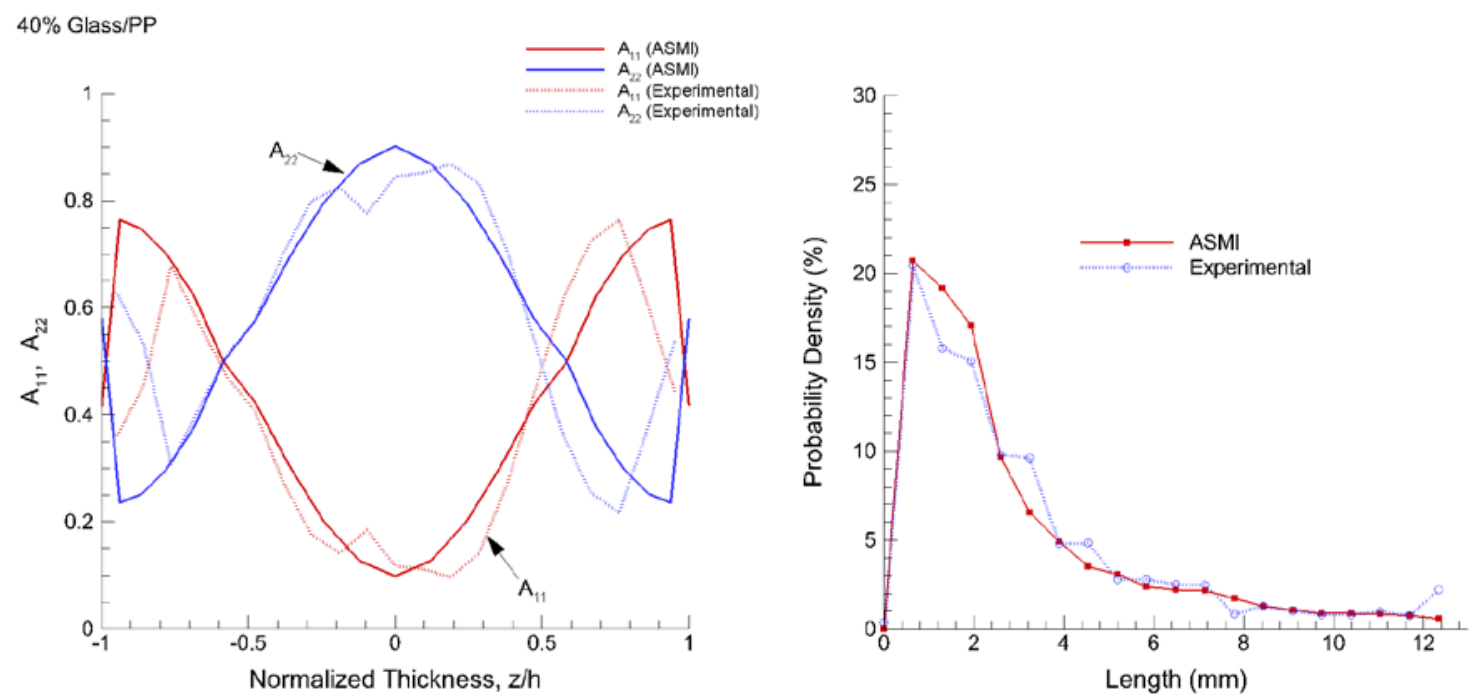

Figure 9. (a) Predicted and measured fiber orientation distribution, and - (b) Predicted and measured fiber length distribution at $35 \mathrm{~mm}$ from the injection center of the long-glass-fiber/PP center-gated disk.

Figures 10(a) and 10(b) illustrate the first principal elastic modulus computed for a 40\%weight-fraction long-glass/PP center-gated disk without and with incorporation of debonding quantified by $\beta=2$, respectively. The results for the second principal elastic modulus are given in Figures 11(a) and 11(b). These results show that partial fiber/matrix debonding after processing causes a significant reduction of elastic moduli in the injection-molded composite. The predicted principal elastic moduli at $35 \mathrm{~mm}$ from the disk center without and with debonding are given in Table 1 that also provides the corresponding measured values. 


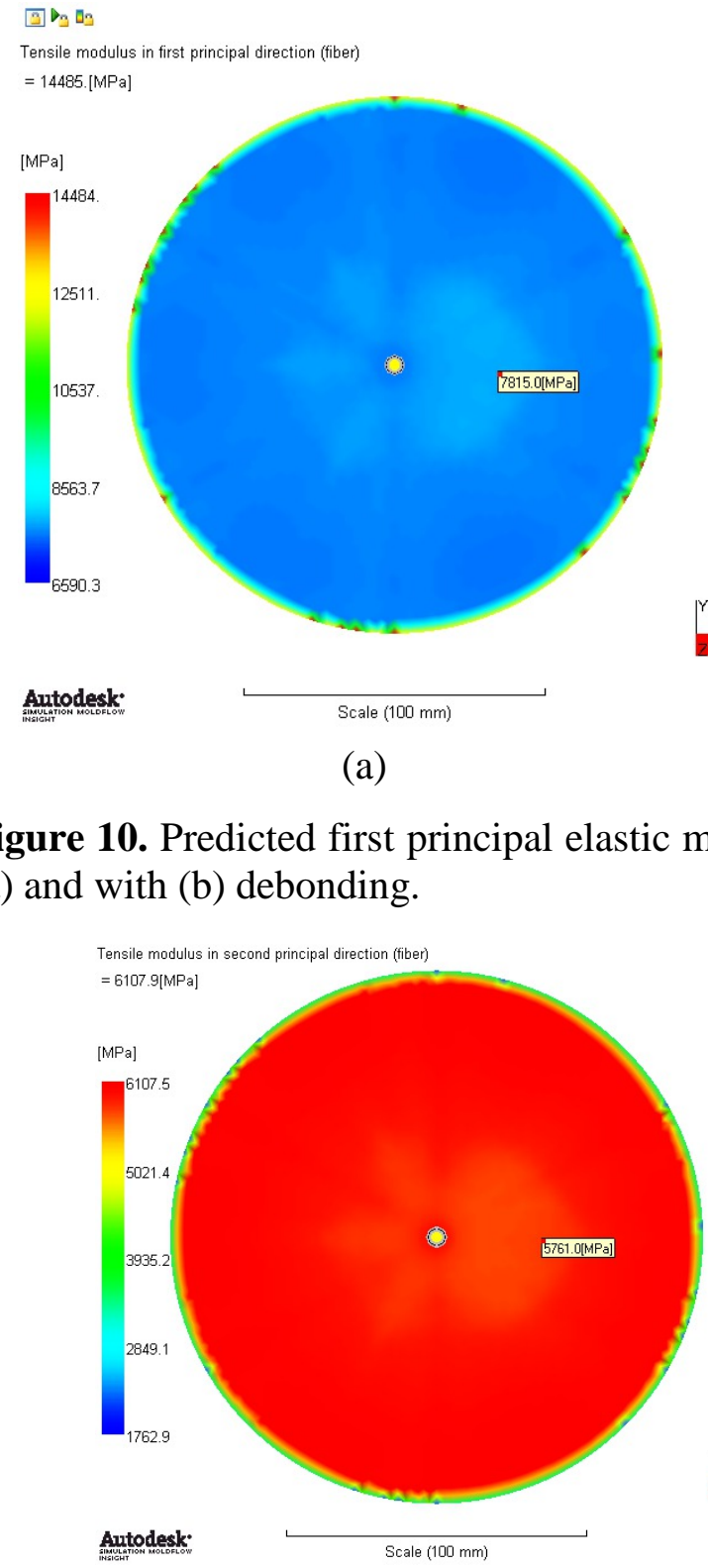

(a)

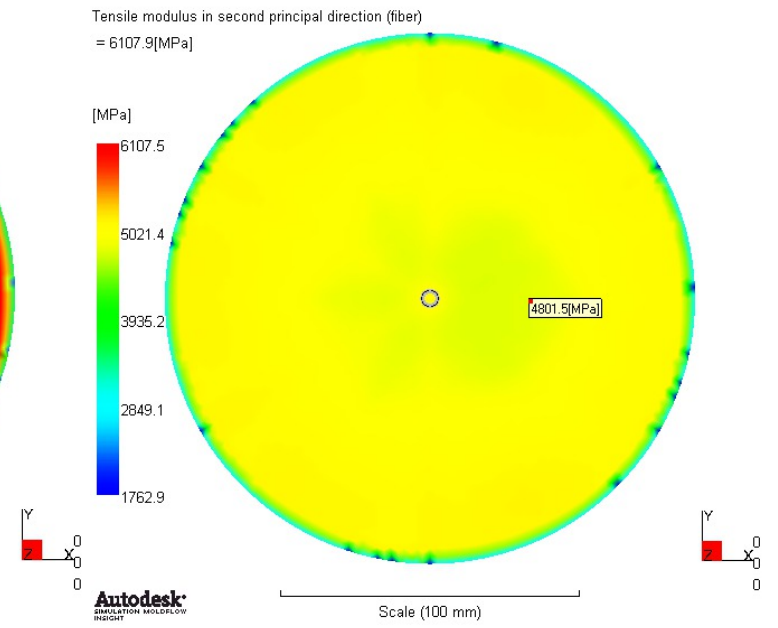

(b)

Figure 11. Predicted second principal elastic modulus $\left(E_{11}\right)$ in a glass/PP disk without (a), and with debonding (b).

\begin{tabular}{|c|c|c|c|}
\hline Modulus (MPa) & Without Debonding & With Debonding $(\boldsymbol{\beta}=\mathbf{2})$ & Experimental [2] \\
\hline $\mathrm{E}_{11}$ & 5761 & 4802 & 5318 \\
\hline $\mathrm{E}_{22}$ & 7815 & 6891 & 7521 \\
\hline
\end{tabular}

Table 1. Predicted and measured principal elastic moduli at $35 \mathrm{~mm}$ from the injection center on the glass/PP center-gated disk. 


\subsection{Stress-Strain Responses and Damage Analysis}

The EMTA-NLA/ABAQUS ${ }^{\circledR}$ analyses were performed that include layered shell modeling and three-dimensional (3-D) modeling of selected LFT specimens using the elastic-plastic damage models of EMTA-NLA to further validate these models for supporting their implementation in Autodesk ${ }^{\circledR}$ Moldflow ${ }^{\circledR}$ Structural Alliance (AMSA).

\subsection{Analyses of Specimens Cut from the Long-glass-fiber/PA6,6 Plaque}

Tensile specimens based on modified ASTM638 Type I Standards were cut along the flow and cross-flow directions from the long-glass-fiber/PA6,6 plaque (analyzed in the previous section) for mechanical testing performed at Oak Ridge National Laboratory (ORNL). Figure 12 shows the locations where the specimens were cut and removed from the plaque. The specimen center is on the plaque centerline at $132 \mathrm{~mm}$ from the gate. Figure 12 also illustrates the mapping results obtained by EMTA-NLA that mapped fiber orientation results from ASMI to the ABAQUS mesh of the tensile specimen for ABAQUS analyses using the layered shell elements.

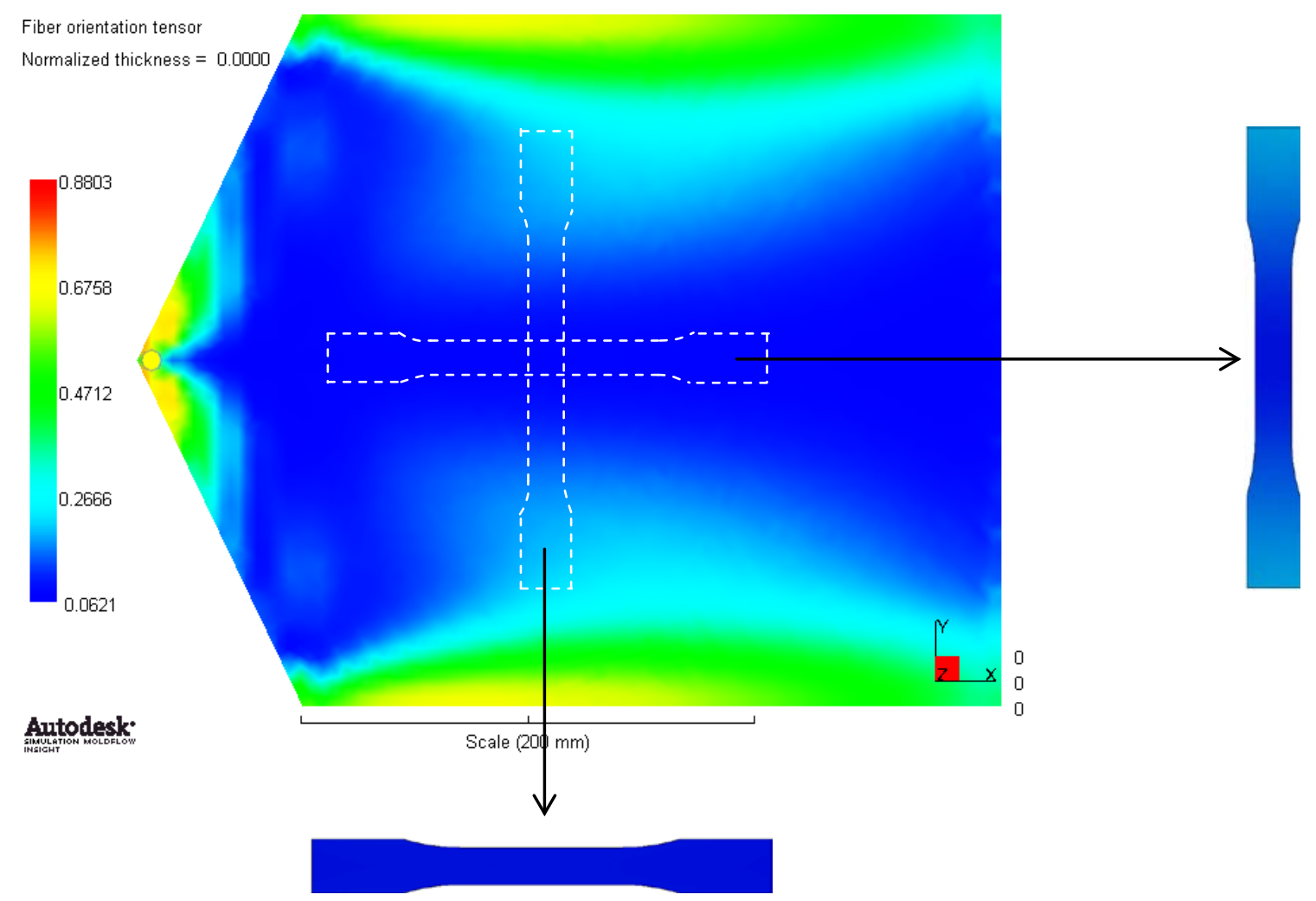

Figure 12. The specimens at the selected location on the glass/PA6,6 plaque were removed and then subjected to tensile loading. This figure also shows ASMI fiber orientation prediction and mapping results for the distribution of $A_{11}$ in a core layer. 
Figure 13(a) shows the damage development in the core layer of the flow-direction specimen at the onset of failure. Total failure occurs when the matrix damage variable attains the critical value ( $D_{\mathrm{c}}=0.3$ for this material). The failure behavior appears to be rather brittle for this material. The brittle character is reflected through small failure strains and little pronounced nonlinearity of the stress-strain curves. More damage accumulations are observed in the specimen end region near the gate due to perturbed flow that affects local fiber orientation. To assess the stress/strain response captured at the specimen center, layered shell and 3-D models of a region representative of the specimen center were also built and analyzed. Figure 13(b) shows the detailed damage distribution in the specimen center predicted by the 3-D modeling using 3-D solid elements of ABAQUS. The 3-D discretization used 21 elements in the thickness direction to capture measured fiber orientation and length at 21 locations through the specimen thickness. As the fibers in the core layers are rather aligned with the cross-flow direction, tensile loading applied in the flow-direction has caused more damage in these layers as well captured by the 3-D model (Figure 13(b)).

(a)

(b)

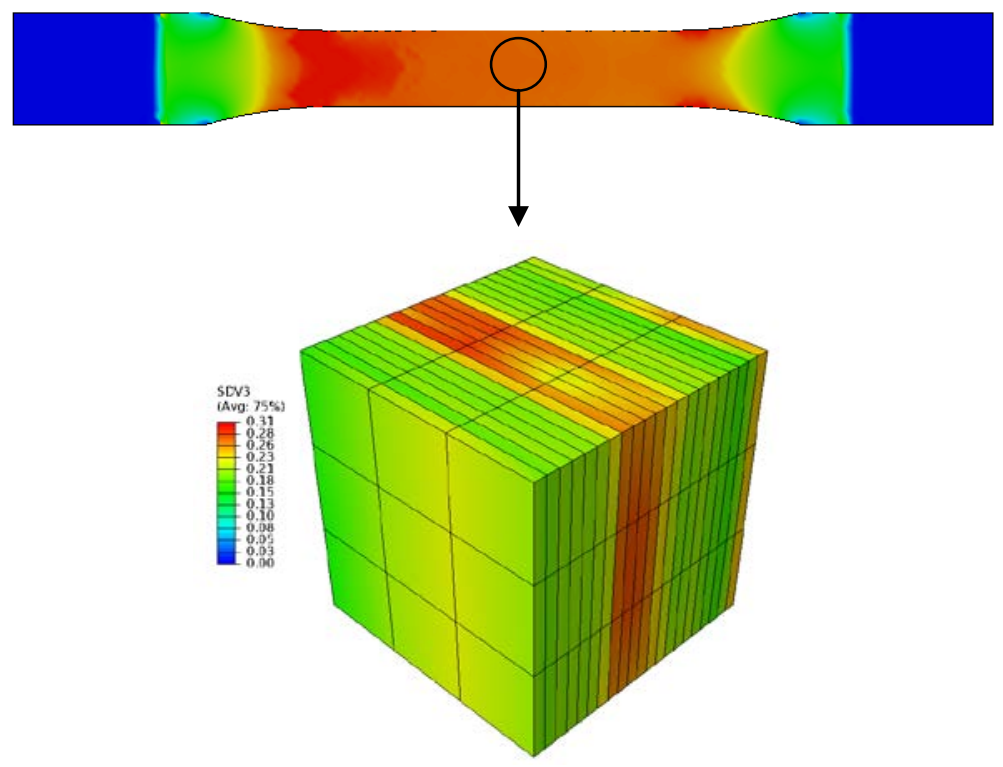

Figure 13. EMTA-NLA/ABAQUS damage analysis of the tensile specimen cut from the glass/PA6,6 plaque along the flow direction (Figure 9) - (b) 3-D analysis of the specimen center.

Figures 14(a) and 14(b) present similar damage analyses for the cross-flow direction specimen (illustrated in Figure 12). Figure 14(a) shows the damage distribution in a shell layer of this specimen. As the fibers in the shell layers are rather oriented in the flow direction, subjected 
to cross-flow direction loading, these layers undergo more pronounced matrix damage as illustrated in Figure 14(b) that provides the 3-D damage distribution predicted for the specimen center.

(a)

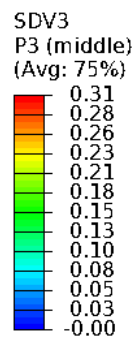

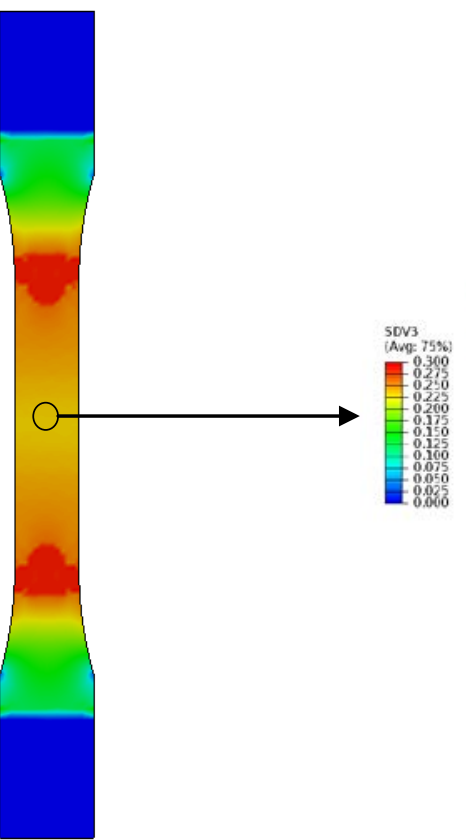

(b)

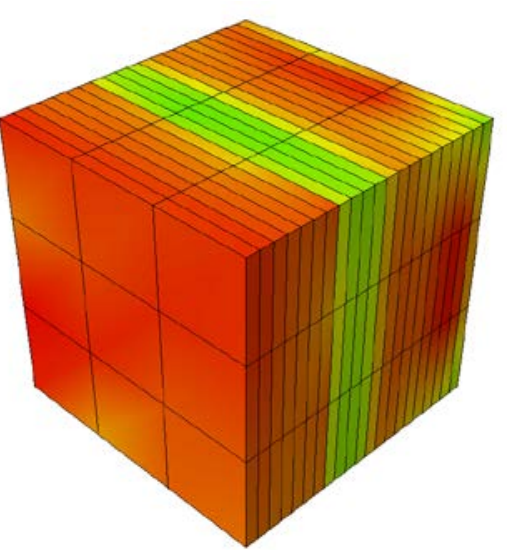

Figure 14. EMTA-NLA/ABAQUS damage analysis of the tensile specimen cut from the glass/PA6,6 plaque along the cross-flow direction (Figure 12) - (b) 3-D analysis of the specimen center.
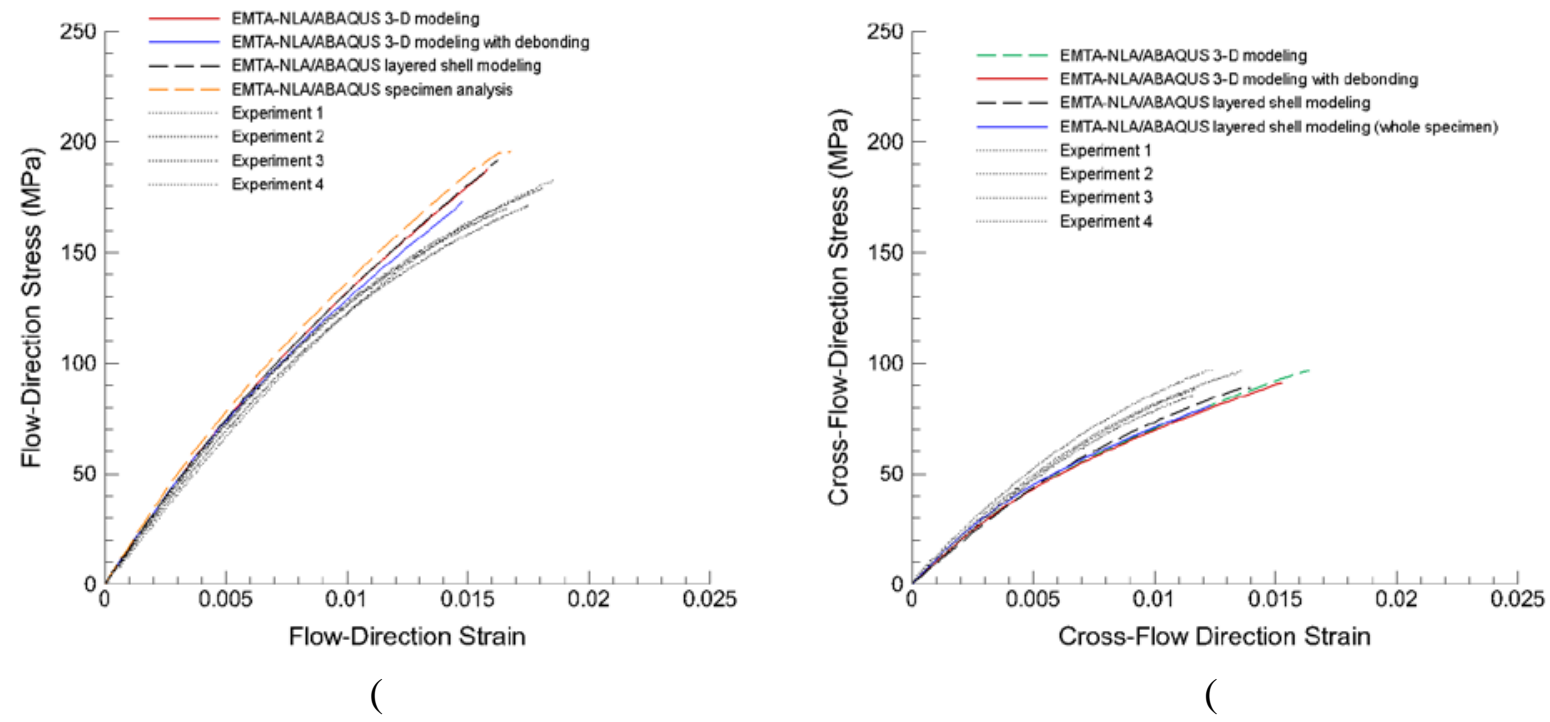

Figure 15. Predicted and measured stress/strain responses recorded at the specimen center: (a) flow-direction responses, and (b) Cross-flow-direction responses. 
Figure 15(a) and 15(b) respectively present the predicted flow- and cross-flow-direction stress/strain responses compared to the experimental results obtained at ORNL under the previous Predictive Engineering PNNL/ORNL effort. All the predicted strengths agree with the average measured strength within $15 \%$, it is noted that accounting for fiber/matrix debonding in addition to matrix damage has improved the stress/strain prediction during the final phase of loading. However, matrix damage is likely the main mechanism that causes failure of this material

\subsection{Analyses of Specimens Cut from the Long-glass-fiber/PP Plaque}

Similar EMTA-NLA/ABAQUS analyses were conducted for the specimens cut from the long-glass-fiber/PP plaques along the flow and cross-flow directions (Figure 16). The specimen center is at $45 \mathrm{~mm}$ from the gate.

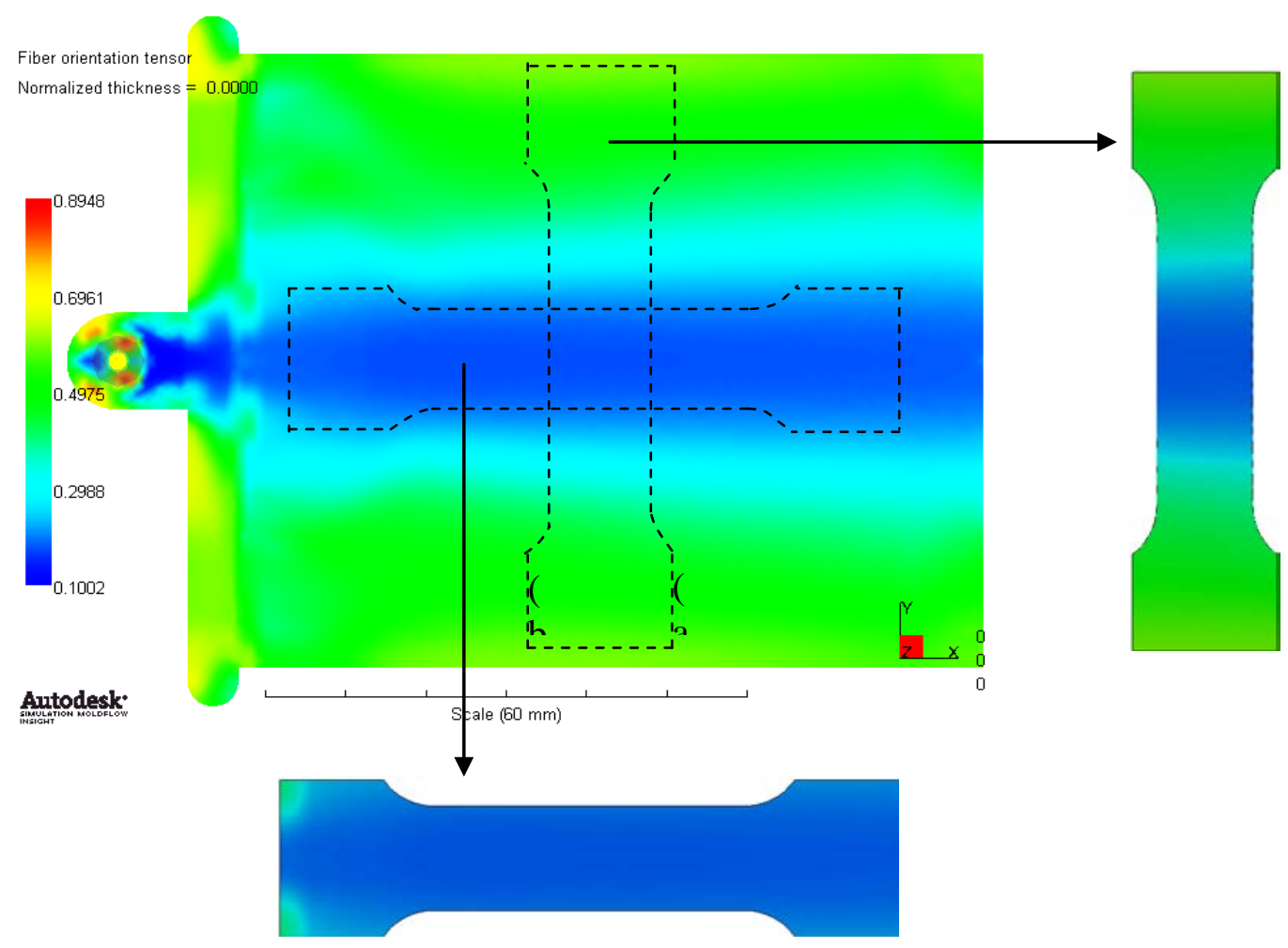

Figure 16. The specimens at the selected location on the glass/PP plaque were removed and then subjected to tensile loading. This figure also shows ASMI fiber orientation prediction and mapping results for the distribution of $A_{11}$ in a core layer.

Figure 17(a) shows the damage development in the core layer of the flow-direction specimen at failure. Total failure occurs when the matrix damage variable attains the critical value ( $D_{\mathrm{c}}=0.9$ for this material). More damage accumulations are observed in the specimen end region near the gate due to perturbed flows that affect local fiber orientation. The dog-bone shape 
has a more pronounced stress concentration effect in this specimen (compared to the previous case, Section 4.1) that contributed to more damage accumulations near the grip regions. To assess the stress/strain response captured at the specimen center, layered shell and 3-D models of a region representative of the specimen center were also built and analyzed. Figure 17(b) shows the detailed damage distribution in the specimen center predicted by the 3-D modeling using 3-D solid elements of ABAQUS.

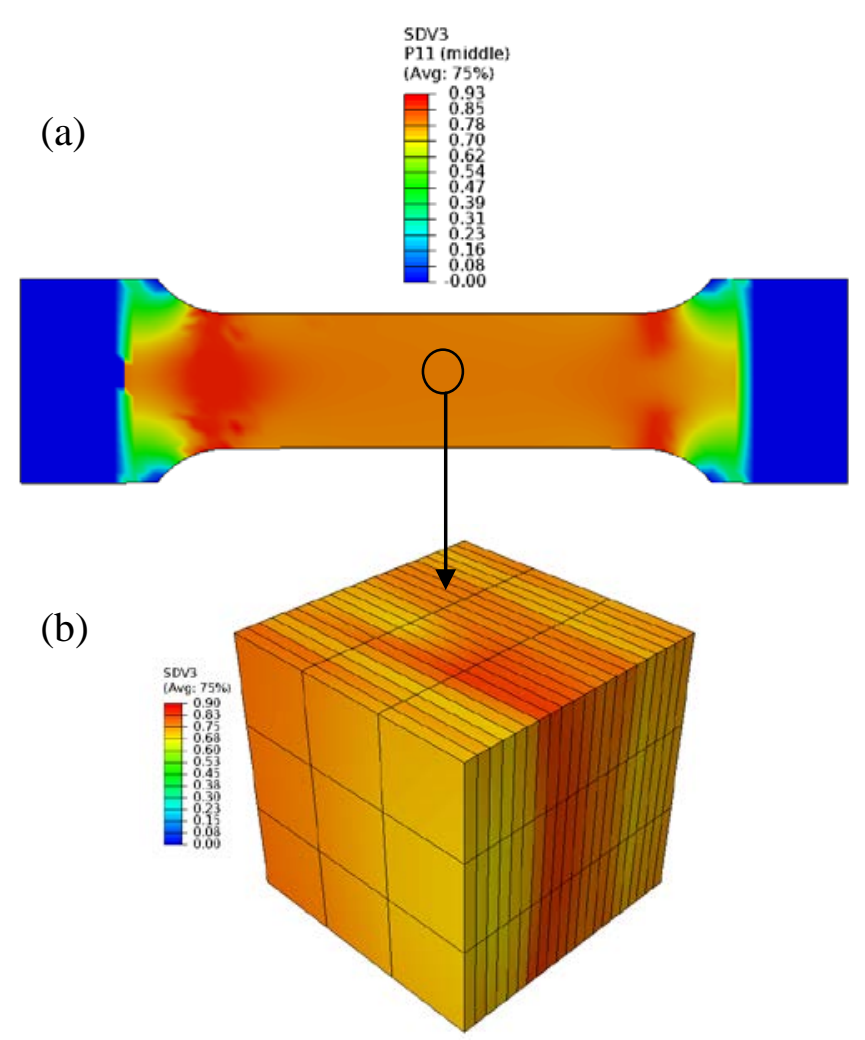

Figure 17. EMTA-NLA/ABAQUS damage analysis of the tensile specimen cut from the glass/PP plaque along the flow direction (Figure 16) - (b) 3-D analysis of the specimen center.

Figures 18(a) and 18(b) present similar damage analyses for the cross-flow direction specimen (illustrated in Figure 16). Figure 18(a) shows the damage distribution in a shell layer of this specimen. Early damage accumulations have been observed at the dog-bone regions while the specimen center has undergone significantly less damage as illustrated in Figure 18(b) that provides the 3-D damage distribution predicted for the specimen center.

Figure 19(a) and 19(b) respectively present the predicted flow- and cross-flow-direction stress/strain responses compared to the ORNL experimental results. All the predicted strengths for the flow-direction specimen agree with the average measured strength within $15 \%$. However, as for the flow-direction specimen, we have noticed the stress concentration effect at the 'dogbone" corners of the cross-flow specimen, and this effect combined with the fiber orientation perturbation along the longitudinal edges of the plaque (i.e. the longitudinal edge walls align the fibers along the walls) has caused early failure of the cross-flow direction specimens. Early 
failure was well captured by the analysis of the whole specimen. As the analysis of the region representing the specimen center ignored these local effects, it then predicted much higher strength levels.

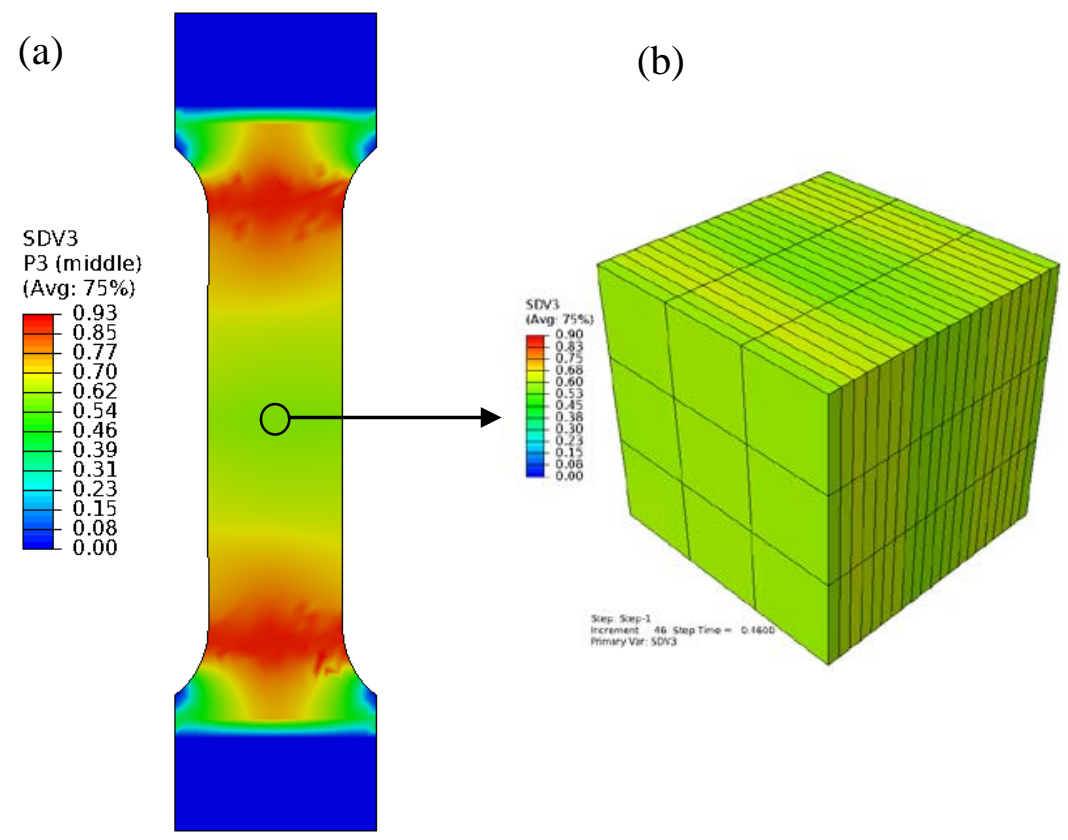

Figure 18. EMTA-NLA/ABAQUS damage analysis of the tensile specimen cut from the glass/PP plaque along the cross-flow direction (Figure 16) - (b) 3-D analysis of the specimen center.
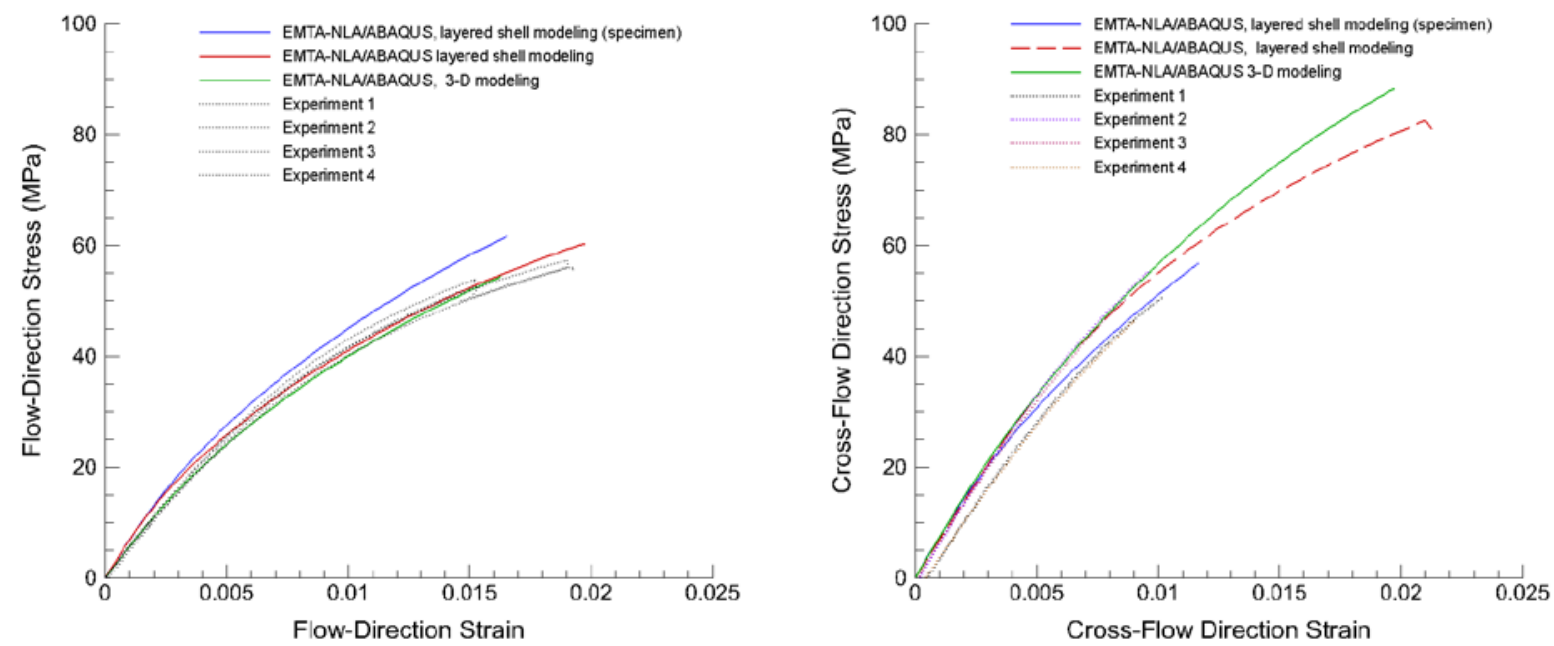

Figure 19. Predicted and measured stress/strain responses recorded at the specimen center: (a) flow-direction responses, and (b) Cross-flow-direction responses. 


\subsection{Conclusions}

The implementation of the EMTA elastic and debonding models in ASMI allows the elastic properties predictions for LFT composite structures for their semi-structural or structural applications. Fiber/matrix debonding significantly affects the mechanical properties (stiffness, stress-strain response, strength, etc.). It is important to achieve good fiber/matrix adhesion to minimize this defect. Future work includes the implementation of the EMTA-NLA elastic-plastic models in AMSA by Autodesk staff for nonlinear analyses of LFT structures using AMSA and a structural finite element analysis code.

\subsection{Acknowledgements}

This work was funded by the US Department of Energy's Office of Vehicle Technologies (Dr. Carol Schutte, Team Lead for Materials Technology). The orientation and length distribution data as well as the mechanical testing results used in this report were generated at the Oak Ridge National Laboratory. The authors would like to thank Mr. Vlastimil Kunc for these data.

\subsection{References}

[1] Nguyen, B.N., Bapanapalli, S.K., Holbery, J.D., Smith, M.T., Kunc, V., Frame, B.J., Phelps, J.H. and Tucker III, C.L. (2008). "Fiber Length and Orientation Distributions in Long-Fiber Injection-Molded Thermoplastics - Part I: Modeling of Microstructure and Elastic Properties.” Journal of Composite Materials, 42:1003-1029.

[2] Nguyen, B.N., Bapanapalli, S.K., Kunc, V., Phelps, J.H., and Tucker III, C.L. (2009). "Prediction of the Elastic-Plastic Stress/Strain Response for Injection-Molded Long-Fiber Thermoplastics." Journal of Composite Materials, 43: 217-246.

[3] Nguyen, B.N. and Kunc, V. (2010). "An Elastic-plastic Damage Model for Long-Fiber Thermoplastics.” International Journal of Damage Mechanics, 19(6):691-725.

[4] Nguyen, B.N., Kunc, V., Bapanapalli, S.K., Phelps, J.H., and Tucker III, C.L. (2009). "Damage Modeling of Injection-Molded Short- and Long-Fiber Thermoplastics." In: Proceedings of the $9^{\text {th }}$ Annual SPE Automotive Composites Conference \& Exhibition, Society of Plastics Engineers.

[5] Nguyen, B.N., Kunc, V., and Bapanapalli, S.K. (2008). "Creep Modeling for InjectionMolded Long-Fiber Thermoplastics.” In Proceedings of the ASME IMECE 2008, Boston, MA, paper \# IMECE2008-66335.

[6] Nguyen, B.N. (2010). “EMTA User’s Guide.” Internal Report, Pacific Northwest National Laboratory, PNNL-20013.

[7] Nguyen, B.N. (2010). “EMTA-NLA User's Guide.” Internal Report, Pacific Northwest National Laboratory, PNNL-19997.

[8] Eshelby, J.D (1957). "The Determination of the Elastic Field of an Ellipsoidal Inclusion and Related Problems." Proceedings of the Royal Society London, A 241: 376-396.

[9] Mori, T. and Tanaka, K. (1973). "Average Stress in Matrix and Average Elastic Energy of Materials with Misfitting Inclusions.” Acta Metallurgica, 21:571-574. 
[10] Benveniste, Y. (1987). “A New Approach to the Application of Mori-Tanaka’s Theory in Composite Materials.” Mechanics of Materials, 6:147-157.

[11] Chen, C.-H. and Cheng, C.-H. (1996). "Effective Elastic Moduli of Misoriented ShortFiber Composites.” International Journal of Solids and Structures, 33: 2519-2539.

[12] Advani, S. and Tucker III, C.L. (1987). "The Use of Tensors to Describe and Predict Fiber Orientation in Short-Fiber Composites." Journal of Rheology, 31: 751-784.

[13] Wetzel, E.D. (1999). Modeling Flow-Induced Microstructure in Inhomogeneous LiquidLiquid Mixtures, Ph.D. thesis, University of Illinois at Urbana-Champaign, Urbana, IL.

[14] Qu, J. (1993). "The Effect of Slightly Weakened Interfaces on the Overall Elastic Properties of Composite Materials.” Mechanics of Materials, 14: 269-281.

[15] Van Hattum, F.W.J. and Bernado, C.A. (1999). "A Model to Predict the Strength of Short Fiber Composite.” Polymer Composites, 20(4): 524-533.

[16] Lemaitre, J. (2002). "Introduction to Continuum Damage Mechanics.” In: Continuum Damage Mechanics of Materials and Structures, Allix, O. and Hild, F., eds., pp. 235-258, Elsevier Science Ltd, Oxford, United Kingdom.

[17] Lemaitre, J. and Chaboche, J.L. (1985). Mécanique des Matériaux Solides, Dunod, Paris.

[18] Han, S., Jin, X., Wang, J., Costa, F., Bendickson, R., and Kaczmarczyk, M. (2012). "The Numerical Analysis and Validation of Compression Molding Process.” In: Proceedings of the $12^{\text {th }}$ Annual SPE Automotive Composites Conference \& Exhibition, Society of Plastics Engineers. 